\title{
Honokiol-induced apoptosis and autophagy in glioblastoma multiforme cells
}

\author{
KEN-HU CHANG $^{1 *}$, MING-DE YAN $^{2 *}$, CHIH-JUNG YAO ${ }^{3}$, PEI-CHUN LIN ${ }^{3}$ and GI-MING LAI ${ }^{3-5}$ \\ ${ }^{1}$ Division of Hematology Oncology, Department of Internal Medicine, Shuang Ho Hospital; ${ }^{2}$ Division of Gastroenterology, \\ Department of Internal Medicine, Wang Fan Hospital; ${ }^{3}$ Center of Excellence for Cancer Research; \\ ${ }^{4}$ Division of Hematology and Medical Oncology, Department of Internal Medicine, Wan Fang Hospital, \\ Taipei Medical University, Taipei 116; ${ }^{5}$ National Institute of Cancer Research, \\ National Health Research Institutes, Miaoli 35053, Taiwan, R.O.C.
}

Received March 8, 2013; Accepted August 9, 2013

DOI: $10.3892 / \mathrm{ol} .2013 .1548$

\begin{abstract}
Honokiol, a hydroxylated biphenyl compound isolated from the Chinese herb Magnolia officinalis, has been reported to have anticancer activities in a variety of cancer cell lines. The present study aimed to evaluate the anticancer effect and possible molecular mechanisms of honokiol in a glioblastoma multiforme (GBM) cell line. The anticancer activities of honokiol were investigated in the DBTRG-05MG GBM cell line. The effect of honokiol on cell growth was determined using a sulforhodamine B assay. Flow cytometry and immunoblotting were used to measure honokiol-induced apoptosis (programmed cell death type I) and autophagy (programmed cell death type II). Honokiol was observed to reduce DBTRG-05MG cell viability in a dose-dependent manner. At a dose of $50 \mu \mathrm{M}$, honokiol markedly decreased the expression of $\mathrm{Rb}$ protein and led to the cleavage of poly(ADP-ribose) polymerase and $\mathrm{Bcl}-\mathrm{xL}$ to promote apoptosis in the cancer cells. In addition, markers of autophagy, including Beclin-1 and LC3-II, were also significantly increased. In addition to apoptosis, honokiol was also able to induce autophagy in the DBTRG-05MG cells. The mechanisms that are responsible for the correlation between honokiol-induced apoptosis and autophagy require further investigation. Such efforts may provide a potential strategy for improving the clinical outcome of GBM treatment.
\end{abstract}

\section{Introduction}

Glioblastoma multiforme (GBM) is the most common and invasive adult malignant brain tumor in humans. Despite

Correspondence to: Dr Gi-Ming Lai, Division of Hematology and Medical Oncology, Department of Internal Medicine, Wan Fang Hospital, Taipei Medical University, no. 111, Section 3, Hsing-Long Road, Taipei 116, Taiwan, R.O.C.

E-mail: gminlai@nhri.org.tw

${ }^{*}$ Contributed equally

Key words: glioblastoma multiforme, honokiol, apoptosis, autophagy standard treatments, including surgery and radiotherapy, which have been administered to patients with GBM in the past decade, the prognosis remains poor, owing to the acquired resistance of the GBM cells to apoptosis (1-3).

In the past decade, the induction of apoptosis (programmed cell death type I) has become the major strategy to combat cancer. However, resistance to apoptosis is considered to be a characteristic of several types of cancers, particularly primary GBM. Therefore, the identification of innovative strategies other than the induction of apoptosis is urgently required. Studies have demonstrated the potential of autophagy (programmed cell death type II) as a target for cancer therapy (4). The most useful chemotherapeutic agent for GBM, temozolomide, has also been reported to exert a proautophagic effect, indicating the importance of autophagy modulation in GBM treatment (5).

With the exception of traditionally synthetic compounds, numerous phytochemicals have been identified to exert anticancer effects. Honokiol, a small molecule biphenolic compound purified from the medicinal herb Magnolia officinalis (Magnoliae Cortex), has been known to exert antithrombotic, antibacterial and anxiolytic effects (6-9). Studies have revealed that honokiol is able to inhibit tumor growth in animals and induce apoptosis in various types of cancer cells, including leukemia, hepatoma, prostate, lung and colon cells (10-13). More recently, honokiol has been shown to be capable of crossing the blood-brain barrier (BBB) and blood-cerebrospinal fluid barrier (BCSFB) and inhibiting brain tumor growth in the human U251 xenograft glioma model (14). However, little is known about the molecular mechanisms underlying the effects of honokiol against glioma cells.

The present study explored the effects of honokiol in DBTRG-05MG GBM cells to investigate whether autophagy is involved in the anticancer effects of the compound.

\section{Materials and methods}

Cell line and cell culture. The human GBM DBTRG-05MG cell line was maintained in RPMI-1640 medium (Gibco, Carlsbad, CA, USA) containing $10 \%$ fetal bovine serum, $0.01 \mathrm{M}$ HEPES and $1 \mathrm{mM}$ sodium pyruvate in a $37^{\circ} \mathrm{C}$ incubator with $5 \% \mathrm{CO}_{2}$. 
Chemicals and reagents. Honokiol was dissolved in dimethyl sulfoxide (DMSO) at a concentration of $50 \mathrm{mM}$ and stored at $-20^{\circ} \mathrm{C}$. Sulforhodamine B (SRB) was dissolved in phosphate buffer at a concentration of $5 \mathrm{mg} / \mathrm{ml}$ and stored at $4^{\circ} \mathrm{C}$. SRB, DMSO and cadmium acetate were purchased from Sigma (St. Louis, MO, USA).

Cell viability assay. The DBTRG-05MG cells were seeded at a density of $3 \times 10^{3}$ cells/well in $96-w e l l$ plates for $24 \mathrm{~h}$. The cells were then treated with various concentrations of honokiol $(6.25,12.5,25$ and $50 \mu \mathrm{M})$ for $72 \mathrm{~h}$. The cell numbers were determined using the SRB assay. Briefly, the cells were fixed in $10 \%$ trichloroacetic acid and stained with $0.4 \% \mathrm{SRB}$, a protein binding dye. Following incubation and washing with $1 \%$ acetic acid, the bound SRB was dissolved in $10 \mathrm{mM}$ unbuffered Tris base and the optical density was measured at $562 \mathrm{~nm}$ using a microtiter plate reader.

Analysis of sub-G $G_{1}$ apoptotic population and cell cycle distribution. One day after being seeded in a 6-well plate $\left(1 \times 10^{5}\right.$ cells $/ \mathrm{ml}, 2 \mathrm{ml} /$ well), the cells were incubated with various concentrations of honokiol $(12.5,25$ and $50 \mu \mathrm{M})$ for $72 \mathrm{~h}$. The control groups were treated with phosphate-buffered saline (PBS) only. Upon harvesting, the cells were fixed in $70 \%$ ice-cold ethanol and stored at $-20^{\circ} \mathrm{C}$. The cells were then washed twice with ice-cold PBS and incubated with RNase and the DNA intercalating dye, propidium iodide $(50 \mu \mathrm{g} / \mathrm{ml})$. The percentages of the sub- $\mathrm{G}_{1}$ apoptotic population and cell cycle distribution were then analyzed using a flow cytometer (BD Biosciences, San Jose, CA, USA).

Western blot analysis. The cells were seeded at density of $1 \times 10^{6}$ cells/dish in a $10-\mathrm{cm}$ dish for $24 \mathrm{~h}$. To prepare the total cell extract, the cells were harvested at $72 \mathrm{~h}$ following the treatment described previously, then washed, lysed with lysis buffer [50 mM Tris- $\mathrm{HCl}$ (pH 7.4) $150 \mathrm{mM} \mathrm{NaCl}, 1 \%$ Triton X-100, 0.5\% deoxycholate, $1 \mathrm{mM}$ ethylenediaminetetraacetic acid (EDTA), $1 \mathrm{mM} \mathrm{Na} \mathrm{VO}_{4}, 1 \mathrm{mM} \mathrm{NaF}$ and $2 \%$ cocktail] and cleared by centrifugation at $12,000 \mathrm{x} \mathrm{g}$ for $30 \mathrm{~min}$ at $4^{\circ} \mathrm{C}$. Briefly, the cell pellets were lysed with protein extraction solution and incubated at $-20^{\circ} \mathrm{C}$ for $20 \mathrm{~min}$. Next, the cell lysates were centrifuged at $15,000 \mathrm{x}$ g for $5 \mathrm{~min}$ and the total protein was collected. The protein concentration was measured using a protein assay kit (Strong Biotech, Taipei, Taiwan). Total protein $(20 \mu \mathrm{g})$ was separated on a $10 \%$ SDS-PAGE gel and transferred to a PVDF membrane. Non-specific binding was blocked using 5\% skimmed milk. Primary antibodies to detect RB (sc-102), poly(ADP-ribose) polymerase (PARP; sc-7150) and Bcl-x (S/L; sc-8392) were purchased from Santa Cruz Biotechnology, Inc. (Santa Cruz, CA, USA). Primary antibodies to phospho-RB (Ser807/811), Beclin-1 (\#3738), LC3 (\#4108) and glyceraldehyde 3-phosphate dehydrogenase (GAPDH; \#2118) were purchased from Cell Signaling Technology (Beverly, MA, USA). The primary antibodies were detected using horseradish peroxidase (HRP)-conjugated anti-mouse, anti-rabbit or anti-goat secondary antibodies as appropriate, for $1 \mathrm{~h}$ at $25^{\circ} \mathrm{C}$. The bound HRP-conjugated secondary antibodies were visualized using an Enhanced Chemiluminescence (ECL) Plus System (Millipore, Billerica, MA, USA).

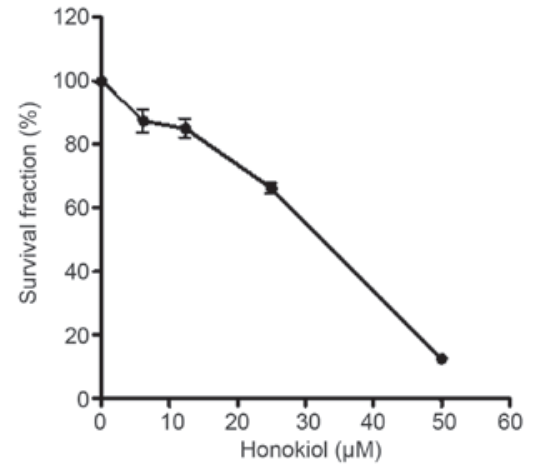

Figure 1. Effect of honokiol on DBTRG-05MG cell viability. The cells were incubated with various concentrations of honokiol for $72 \mathrm{~h}$. The cell viability was determined by sulforhodamine B (SRB) assay.

\section{Results}

Honokiol inhibits the growth of GBM cells and induces apoptosis. The SRB assay revealed that honokiol inhibited the growth of the DBTRG-05MG cells in a dose-dependent manner. Following $72 \mathrm{~h}$ of treatment, the $\mathrm{IC}_{50}$ of honokiol on the DBTRG-05MG cells was $\sim 30 \mu \mathrm{M}$ (Fig. 1). To investigate the apoptotic effects of honokiol on the GBM cells, the percentage of the apoptotic sub- $\mathrm{G}_{1}$ fraction was analyzed using a flow cytometer. Following the treatment with honokiol for $72 \mathrm{~h}$, the percentage of the apoptotic sub- $\mathrm{G}_{1}$ fraction was 9.02, 11.48, 12.42 or $53.55 \%$ in the control and the cells treated with $12.5,25$ and $50 \mu \mathrm{M}$ of honokiol, respectively (Fig. 2). A marked increase in the apoptotic fraction was not observed in the cells that were treated with $\leq 25 \mu \mathrm{M}$ honokiol. When the dose increased to $50 \mu \mathrm{M}$, a massive sub- $\mathrm{G}_{1}$ fraction was observed, indicating that apoptosis only occurred at higher doses of honokiol (Fig. 2).

Honokiol-induced apoptosis of GBM cells is associated with the downregulation of the Rb protein and cleavage of PARP and $B c l-x(S / L)$. To improve our understanding of the events that are involved in honokiol-induced apoptosis, the effects of honokiol on the $\mathrm{Rb}, \mathrm{PARP}$ and $\mathrm{Bcl}-\mathrm{x}(\mathrm{S} / \mathrm{L})$ proteins, which are known to regulate cell apoptotic cascades, were examined. At a dose of $25 \mu \mathrm{M}$, honokiol markedly decreased the phospho-Rb level, but did not significantly affect the total Rb level (Fig. 3). However, honokiol significantly decreased the phospho- and total $\mathrm{Rb}$ proteins when the dose reached $50 \mu \mathrm{M}$. This phenomenon was paralleled with the high level of apoptosis induced by the higher dose $(50 \mu \mathrm{M})$ of honokiol shown in Fig. 2. Consistent with this, the cleavage of PARP, an apoptotic marker, and anti-apoptotic protein Bcl-x (S/L) were only observed in the cells that were treated with $50 \mu \mathrm{M}$ honokiol (Fig. 4).

Honokiol increases the level of autophagy markers in GBM cells. To investigate if autophagy was involved in the honokiol-induced effects against GBM cells, the protein levels of two hallmarks of autophagy, namely Beclin-1 and MAP1LC3A (microtubule-associated protein 1A/1B light chain 3), were examined in the honokiol-treated cells. Honokiol markedly increased the levels of Beclin-1 and LC3-II at $50 \mu \mathrm{M}$ (Fig. 5). Compared with the results that are shown in Figs. 2-4, as in the induction of apoptosis, autophagy was also markedly triggered 

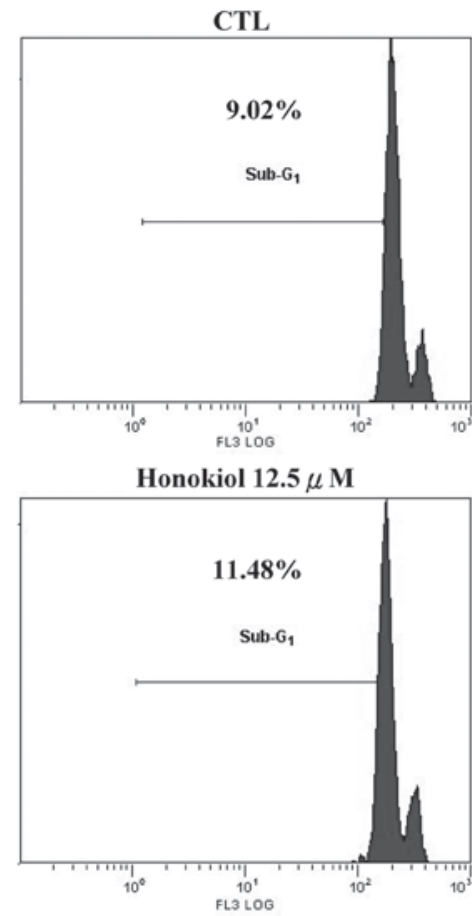

Honokiol $25 \mu \mathrm{M}$

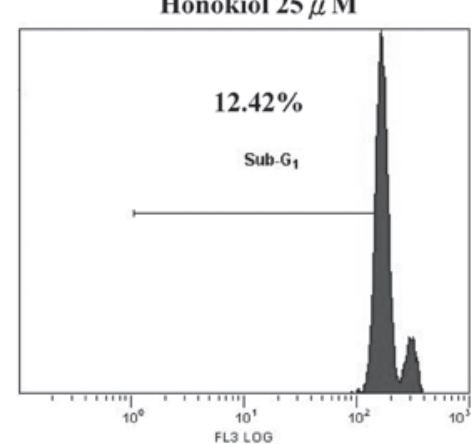

Honokiol $50 \mu \mathrm{M}$

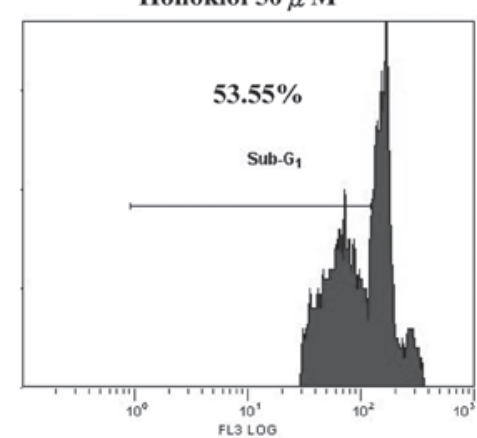

Figure 2. Honokiol-induced apoptosis in DBTRG-05MG cells. Following treatment with various concentrations of honokiol $(0,12.5,25$ and $50 \mu \mathrm{M})$ for $72 \mathrm{~h}$, the cells were examined for apoptosis using propidium iodide (PI) staining and flow cytometry. The percentages of the apoptotic populations are shown in the histograms.

by honokiol at a dose of $50 \mu \mathrm{M}$. The proautophagic effects of honokiol may play a crucial role in the anticancer effects against GBM cells.

\section{Discussion}

To date, there have been no effective therapeutics for the treatment of GBM. Innovative strategies and agents must be investigated in order to conquer this life threatening disease.
Honokiol ( $\mu \mathrm{M})$

\begin{tabular}{lllll}
\hline $\mathbf{0}$ & $\mathbf{1 2 . 5}$ & $\mathbf{2 5}$ & $\mathbf{5 0}$ & \\
\hline & & & & phospho-Rb \\
\hline & & & & \\
\hline & & & total-Rb \\
\hline & & & GAPDH
\end{tabular}

Figure 3. Effects of honokiol on Rb protein. The DBTRG-05MG cells were treated with honokiol at the indicated concentrations for $72 \mathrm{~h}$ and a western blot analysis was performed with antibodies that were specific for phospho- and total Rb protein. Glyceraldehyde 3-phosphate dehydrogenase (GAPDH) was used as internal control.

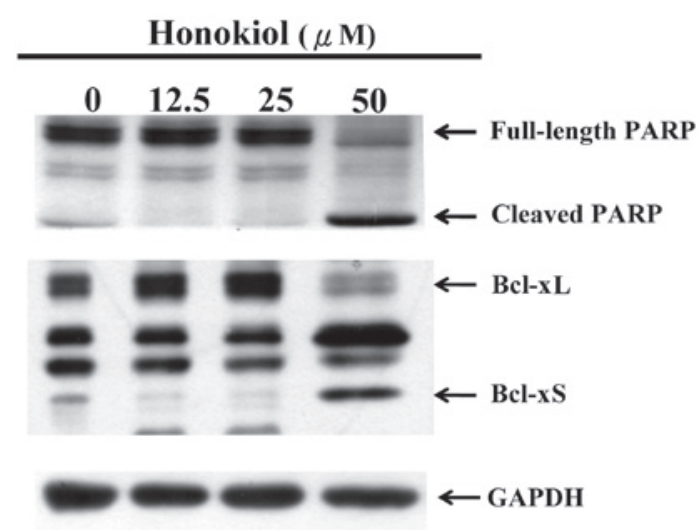

Figure 4. Effects of honokiol-induced cleavage in apoptosis-related proteins The DBTRG-05MG cells were treated with honokiol at the indicated concentrations for $72 \mathrm{~h}$ and a western blot analysis was performed with antibodies that were specific for poly(ADP-ribose) polymerase (PARP) and Bcl-x (S/L). GAPDH, glyceraldehyde 3-phosphate dehydrogenase.

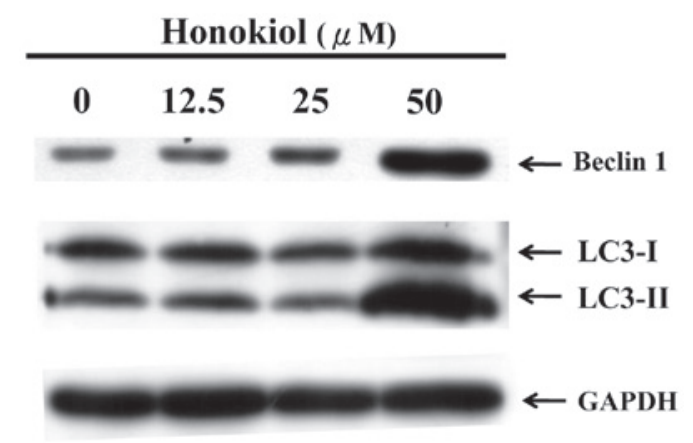

Figure 5. Honokiol-induced autophagy in DBTRG-05MG cells. The cells were treated with honokiol at the indicated concentrations for $72 \mathrm{~h}$ and a western blot analysis was performed with antibodies that were specific for Beclin-1 and LC3. GAPDH, glyceraldehyde 3-phosphate dehydrogenase.

Honokiol has been shown to exert antitumor effects in various types of cancer in animals $(15,16)$. Furthermore, the toxicity of honokiol in normal peripheral blood mononuclear cells (PBMNCs) or primary cultured human cells is relatively low (17). As honokiol has been demonstrated to be able to cross the BBB and inhibit the growth of glioma in animal models, it may be regarded as a potential innovative therapy for treating GBM. However, little is known about the molecular mechanisms underlying the effects against glioma cells (14).

The present study explored the effects of honokiol in DBTRG-05MG GBM cells and demonstrated that type I 
(apoptosis) and II (autophagy) programmed cell death were involved in the effects against the cells. Consistent with other studies, the present data revealed that honokiol was able to induce apoptosis in the GBM cells, as reflected by the appearance of a massive apoptotic sub- $\mathrm{G}_{1}$ fraction. Hyperphosphorylation is able to inactivate the inhibitory effect of Rb on the E2F-1 transcription factor, leading to the progression of the cell cycle. The marked inhibition of phospho-Rb by honokiol at $25 \mu \mathrm{M}$ may contribute to the significant decrease of GBM cell number at this dose without the significant induction of apoptosis. Chau and Wang (18) reported that the loss of phospho- and total Rb protein may sensitize cells to the induction of apoptosis. Similarly, in the present study, honokiol decreased the level of phospho- and total $\mathrm{Rb}$ proteins during the induction of apoptosis at a dose of $50 \mu \mathrm{M}$. In addition, the cleavage of PARP and anti-apoptotic protein $\mathrm{Bcl}-\mathrm{x}(\mathrm{S} / \mathrm{L})$ at this dose further confirmed this phenomenon. According to the literature, the cleavage of Bcl-x $(\mathrm{S} / \mathrm{L})$ is dependent on the activation of caspase-3-like protease $(19,20)$. Thus, the cleaved Bcl-x (S/L) that was observed in the results of the present study indicated that caspase-3-dependent apoptosis may have occurred in the honokiol-treated GBM cells.

In addition to apoptosis, autophagy has been shown to be a potential target for cancer therapy. Proautophagic drugs are a promising class of compounds for counteracting tumor progression by favoring cancer cell death (21). A variety of chemicals, including temozolomide, the most effective agent for GBM treatment, have been reported to induce autophagy (22). In the present study, a marked honokiol-induced increase of the two hallmarks of autophagy, Beclin-1 and LC3-II, indicated the autophagy-inducing effects on the GBM cells. Depending on the magnitude of the induction of autophagy, honokiol may exert the effects of autophagic survival or cell death (23). Autophagy is a double-edged sword in tumorigenesis $(24,25)$. As the marked autophagy of GBM cells was also triggered during the induction of apoptosis by honokiol at a dose of $50 \mu \mathrm{M}$ in the present study, the modulation of autophagy by combining the compound with other agents may profoundly affect honokiol-induced cell death or apoptosis. Therefore, further investigation into a potential strategy combining the effects of autophagic modulating agents with honokiol in GBM cells is warranted.

\section{Acknowledgements}

This study was supported by a grant from the Department of Health, Taiwan (no. DOH99-TD-C-111-008).

\section{References}

1. Maher EA, Furnari FB, Bachoo RM, Rowitch DH, Louis DN, Cavenee WK and DePinho RA: Malignant glioma: genetics and biology of a grave matter. Genes Dev 15: 1311-1333, 2001.

2. Morandi E, Severini C, Quercioli D, D'Ario G, Perdichizzi S, Capri M, Farruggia G, Mascolo MG, Horn W, Vaccari M, Serra R, Colacci A and Silingardi P: Gene expression time-series analysis of camptothecin effects in U87-MG and DBTRG-05 glioblastoma cell lines. Mol Cancer 7: 66, 2008.

3. Chang LF, Lin PC, Ho LI, Liu PY, Wu WC, Chiang IP, Chang HW, Lin SZ, Harn YC, Harn HJ and Chiou TW: Overexpression of the orphan receptor Nur77 and its translocation induced by PCH4 may inhibit malignant glioma cell growth and induce cell apoptosis. J Surg Oncol 103: 442-450, 2011.

4. Long JS and Ryan KM: New frontiers in promoting tumour cell death: targeting apoptosis, necroptosis and autophagy. Oncogene 31: 5045-5060, 2012.
5. Torres S, Lorente M, Rodríguez-Fornés F, Hernández-Tiedra S, Salazar M, García-Taboada E, Barcia J, Guzmán M and Velasco G: A combined preclinical therapy of cannabinoids and temozolomide against glioma. Mol Cancer Ther 10: 90-103, 2011.

6. Hahm ER, Arlotti JA, Marynowski SW and Singh SV: Honokiol, a constituent of oriental medicinal herb magnolia officinalis, inhibits growth of PC-3 xenografts in vivo in association with apoptosis induction. Clin Cancer Res 14: 1248-1257, 2008.

7. Bai X, Cerimele F, Ushio-Fukai M, Waqas M, Campbell PM, Govindarajan B, Der CJ, Battle T, Frank DA, Ye K, Murad E, Dubiel W, Soff G and Arbiser JL: Honokiol, a small molecular weight natural product, inhibits angiogenesis in vitro and tumor growth in vivo. J Biol Chem 278: 35501-35507, 2003.

8. Munroe ME, Arbiser JL and Bishop GA: Honokiol, a natural plant product, inhibits inflammatory signals and alleviates inflammatory arthritis. J Immunol 179: 753-763, 2007.

9. Park J, Lee J, Jung E, Park Y, Kim K, Park B, Jung K, Park E, Kim J and Park D: In vitro antibacterial and anti-inflammatory effects of honokiol and magnolol against Propionibacterium sp. Eur J Pharmacol 496: 189-195, 2004.

10. Chen F, Wang T, Wu YF, Gu Y, Xu XL, Zheng S and Hu X: Honokiol: a potent chemotherapy candidate for human colorectal carcinoma. World J Gastroenterol 10: 3459-3463, 2004.

11. Wang T, Chen F, Chen Z, Wu YF, Xu XL, Zheng S and Hu X: Honokiol induces apoptosis through $\mathrm{p} 53$-independent pathway in human colorectal cell line RKO. World J Gastroenterol 10: 2205-2208, 2004.

12. Konoshima T, Kozuka M, Tokuda H, Nishino H, Iwashima A, Haruna M, Ito K and Tanabe M: Studies on inhibitors of skin tumor promotion, IX. Neolignans from Magnolia officinalis. J Nat Prod 54: 816-822, 1991.

13. Xu D, Lu Q and Hu X: Down-regulation of P-glycoprotein expression in MDR breast cancer cell MCF-7/ADR by honokiol. Cancer Lett 243: 274-280, 2006.

14. Wang X, Duan X, Yang G, Zhang X, Deng L, Zheng H, Deng C, Wen J, Wang N, Peng C, Zhao X, Wei Y and Chen L: Honokiol crosses $\mathrm{BBB}$ and $\mathrm{BCSFB}$, and inhibits brain tumor growth in rat 9L intracerebral gliosarcoma model and human U251 xenograft glioma model. PLoS One 6: e18490, 2011.

15. Chilampalli S, Zhang X, Fahmy H, Kaushik RS, Zeman D, Hildreth MB and Dwivedi C: Chemopreventive effects of honokiol on UVB-induced skin cancer development. Anticancer Res 30: 777-783, 2010.

16. Li Z, Liu Y, Zhao X, Pan X, Yin R, Huang C, Chen L and Wei Y: Honokiol, a natural therapeutic candidate, induces apoptosis and inhibits angiogenesis of ovarian tumor cells. Eur J Obstet Gynecol Reprod Biol 140: 95-102, 2008.

17. Battle TE, Arbiser J and Frank DA: The natural product honokiol induces caspase-dependent apoptosis in B-cell chronic lymphocytic leukemia (B-CLL) cells. Blood 106: 690-697, 2005.

18. Chau BN and Wang JY: Coordinated regulation of life and death by RB. Nat Rev Cancer 3: 130-138, 2003.

19. Fujita N, Nagahashi A, Nagashima K, Rokudai S and Tsuruo T: Acceleration of apoptotic cell death after the cleavage of Bcl-XL protein by caspase-3-like proteases. Oncogene 17: 1295-1304, 1998.

20. Itoh M, Chiba H, Noutomi T, Takada E and Mizuguchi J: Cleavage of Bax-alpha and $\mathrm{Bcl}-\mathrm{x}(\mathrm{L})$ during carboplatin-mediated apoptosis in squamous cell carcinoma cell line. Oral Oncol 36: 277-285, 2000.

21. Lefranc F, Facchini V and Kiss R: Proautophagic drugs: a novel means to combat apoptosis-resistant cancers, with a special emphasis on glioblastomas. Oncologist 12: 1395-1403, 2007.

22. Eimer S, Belaud-Rotureau MA, Airiau K, Jeanneteau M, Laharanne E, Véron N, Vital A, Loiseau H, Merlio JP and Belloc F: Autophagy inhibition cooperates with erlotinib to induce glioblastoma cell death. Cancer Biol Ther 11: 1017-1027, 2011.

23. Kang R, Zeh HJ, Lotze MT and Tang D: The Beclin 1 network regulates autophagy and apoptosis. Cell Death Differ 18: 571-580, 2011.

24. Wu WK, Coffelt SB, Cho CH, Wang XJ, Lee CW, Chan FK, Yu J and Sung JJ: The autophagic paradox in cancer therapy. Oncogene 31: 939-953, 2012.

25. Chen N and Karantza V: Autophagy as a therapeutic target in cancer. Cancer Biol Ther 11: 157-168, 2011. 